12. Цуканов Б.И. Восприятие времени и спортивная специализация // Теория и практика физической культуры. 1988. № 10. С. 32-35.

13. Платонов В.Н. Общая теория подготовки спортсменов в олимпийском спорте. Киев: Олимпийская литература, 1997. 584 с.

14. Ильин Е.П. Психология индивидуальных различий. СПб.: Питер, 2004. 701 с.

15. Берестецкая Н.Ю. Методика технической подготовки пловцов с учетом возрастных особенностей формирования двигательной функции: автореф. дис. ... канд. пед. наук. Киев, 1987. 24 с.

16. Солодков А.С., Сологуб Е.Б. Физиология человека. Общая. Спортивная. Возрастная. М.: Терраспорт, Олимпия Пресс, 2001. 502 с.

17. Уилмор Д.К., Костил Д.А. Физиология спорта. Киев: Олимпийская литература, 2001. 421 с.
18. Тэлбот Д. Как плыть быстрее. М.: Физкультура и спорт, 1978. 88 с.

19. Фомин Н.А., Вавилов Ю.Н. Физиологические основы двигательной активности. М.: Физкультура и спорт, $1991.224 \mathrm{c}$.

20. Погребной А.И., Маркевич Е.Г. Влияние целевых заданий на обобщенные характеристики техники плавания // Актуальные вопросы физической культуры и спорта: Труды науч.-исслед. ин-та проблем физкультуры и спорта. Краснодар: КубГАФК, 1998. C. $74-83$.

21. Биневский Д.А. Возрастные особенности формирования спортивно-технических навыков у пловцов учебно-тренировочных групп ДЮСШ: автореф. дис. ... канд. пед. наук. М., 1993. 22 с.

\title{
METHODOLOGICAL ASPECTS OF SPECIALIZED PERCEPTIONS EVALUATION OF YOUNG SWIMMERS WITH VARIOUS SPORTS SKILLS
}

(C) 2016

M.A. Vershinin, doctor of pedagogical sciences, professor of Theory and Methods of Physical Education Department M.V. Pinyasova, postgraduate student of Theory and Methods of Physical Education Department Volgograd State Physical Education Academy, Volgograd (Russia)

Abstract. On the basis of scientific and methodical literature extensive review the authors analyze formation and development of specialized perceptions of young swimmers with different skills: a sense of time, a sense of pace and space, demonstrated both on land and in water. Two directions that are most appropriate for young swimmers' specialized perceptions measurements are described: 1) to determine characteristics of absolute sensitivity thresholds of individual analyzers under indifferent activity; 2) to analyze specialized perceptions by performing special tasks in specific conditions of motor activities. One component of the so-called «sense of water» is «relative pitch», which evaluates a swimmer's ability to feel water support and is calculated in terms of technique efficiency coefficient. Body position during swimming can be assessed by stroke effort efficiency factor, which shows the ability of an athlete to make the most streamlined position. As a result it is stated that special perception of tempo, time and space for young crawl swimmers do not depend on athlete age and have considerable individual differences. The results of experimental work show that there is only one sensitive period of time to improve a sense of tempo in water and on land (at the age of 1011) and a favorable age period to improve a sense of time in water (at the age of 11-12).

Keywords: swimming; movement technique in swimming; young swimmers' specialized perception; swimmers' sports training; motor technique formation of swimmers.

\section{СИНЕРГЕТИЧЕСКИЙ АСПЕКТ ФОРМИРОВАНИЯ ДИСКУРСИВНОЙ ИНОЯЗЫЧНОЙ КОМПЕТЕНЦИИ БУДУЩИХ БАКАЛАВРОВ НЕЯЗЫКОВЫХ НАПРАВЛЕНИЙ ПОДГОТОВКИ}

(C) 2016

А.Г. Горбунов, доцент кафедры профессионального иностранного языка для гуманитарных специальностей Удмуртский государственный университет, Ижевск (Россия)

\footnotetext{
Аннотация. В статье описан подход к решению проблемы, касающейся разработки и внедрения методов совершенствования иноречевых умений будущих бакалавров неязыковых направлений подготовки. По мнению автора, разработчики современных учебных комплексов должны преследовать цель сформировать у студентов способность к смысловосприятию и смыслопорождению, т. е. умение декодировать и порождать дискурсы на иностранном языке через формирование дискурсивной иноязычной компетенции, что требует внедрения в образовательный контекст специальных педагогических условий, модели и технологии как способа реализации различных инвариантов подходов к формированию искомой компетенции в системе подготовки бакалавров неязыкового профиля. Выявление таких педагогических условий, разработка модели процесса формирования искомой компетенции представляются возможными за счёт синергии филологической и педагогической науки, которая позволяет объяснить и закрепить у студента понимание того, как язык общения реализуется на практике, а сформированный в процессе обучения продвинутый и высокий уровень дискурсивной иноязычной компетенции предопределяет способность будущих бакалавров к эффективной иноречевой коммуникации на межличностные и профессиональные темы. Этому же способствует возможность переобучения студентов неязыкового профиля с модели коммуникации на родном языке на англосаксонскую модель коммуникации. В сумме, понимание природы дискурса, его системных характеристик, алгоритма речевых действий со-
} 
образно англосаксонской модели речевого взаимодействия позволяют методологически обоснованно дать определение термину «дискурсивная иноязычная компетенция» в педагогических целях. Решение проблемы формирования искомой компетенции обеспечивает будущим бакалаврам комфортное вхождение в профессию на уровне международных контактов и дальнейшее развитие их образовательной траектории за счёт продвинутого и высокого уровня владения дискурсивными практиками, соотнесёнными с англосаксонской моделью речевого взаимодействия. Более того, знание и способность будущих бакалавров к использованию дискурсивных иноязычных практик имеет ретроспективный эффект на модель речевого взаимодействия на родном языке.

Ключевые слова: дискурсивная иноязычная компетенция; синергия филологической и педагогической науки; образовательный контекст; будущие бакалавры неязыковых направлений подготовки; иноречевая коммуникация; природа дискурса; системные характеристики дискурса; англосаксонская модель речевого взаимодействия; дискурсивная формула; образовательная траектория.

Основная образовательная программа обучения бакалавров неязыковых направлений подготовки содержит требование сформировать способность студентов к осуществлению профессионально-ориентированной коммуникации с представителями зарубежных профессиональных сообществ, а также умение работать с источниками профессиональных знаний на иностранном языке. В этой связи отметим, что в настоящее время система профессионального образования столкнулась с необходимостью оказывать будущим бакалаврам активное содействие в формировании комплекса компетенций, способствующих эффективному межличностному и профессиональноориентированному речевому взаимодействию на иностранном языке как в условиях учебного занятия, так и в ходе самостоятельной подготовки. Если при выполнении обучающимися письменных работ отмечают в основном удовлетворительное качество, то при непосредственном спонтанном устном иноречевом взаимодействии значительная часть будущих бакалавров демонстрирует низкий уровень готовности и способности к решению поставленных перед ними учебных коммуникативных задач.

Такое положение дел объясняется отсутствием или недостаточной сформированностью дискурсивной иноязычной компетенции, которая в значительной степени предопределяет способность студента воспринимать и порождать речевое произведение на иностранном языке в формате монолога/диалога [1]. Более того, продвинутый и высокий уровень сформированности дискурсивной иноязычной компетенции во многом обусловливает способность будущего бакалавра успешно решать широкий спектр коммуникативных задач на иностранном языке в ходе межличностного и профессионально-ориентированного общения и избегать коммуникативных сбоев в ходе интерлокуции. Необходимость формирования дискурсивной иноязычной компетенции отмечают многие исследователи (Н.И. Алмазова, И.Б. Ворожцова, Н.Д. Гальскова, Н.И. Гез, И.А. Зимняя, Е.И. Пассов, Е.Н. Соловова, П.В. Сысоев и др.), которые разрабатывают и внедряют методы совершенствования иноречевых умений в систему высшего профессионального образования и полагают, что «дискурсивная иноязычная компетенция является целью системы современного образования в области обучения иностранным языкам» [2].

Формирование иноречевых компетенций в системе подготовки бакалавров неязыкового профиля имеет большую степень актуальности, так как в подавляющем большинстве случаев учебные комплексы преследуют цель сформировать у студентов умение воспринимать и воспроизводить тексты как образец реа- лизации речевой интенции по той или иной теме, но не подразумевают формирование у обучающихся умения декодировать и порождать дискурсы, т.е. способности к смысловосприятию и смыслопорождению, соотнесённому в ходе коммуникации с реалиями межличностного и профессионального характера, которые способствуют возникновению экстралингвистического фактора коммуникации, который в свою очередь развивает когнитивные навыки и позволяет обучающимся "заглянуть" за рамки контекста коммуникации.

Полагаем, что существуют объективные дискурсивные основания обучения иностранному языку, так как понятие «дискурс» существует самостоятельно, из чего следует, что при обучении речевому взаимодействию на иностранном языке нельзя ограничивать учебный процесс только формированием умения воспринимать и порождать текст. Постулирование идеи о том, что для будущего бакалавра ключевой компетенцией, обеспечивающей успешную коммуникацию на иностранном языке, является умение реализовать различные дискурсивные практики в ходе иноречевого взаимодействия, приводит нас к умозаключению, которое предопределяет необходимость обращения к последним достижениям в области теории дискурса для выработки единого методологически обоснованного подхода при разработке терминологического аппарата, к пониманию сущности компетенции, которую необходимо сформировать, и определению в педагогических целях самого понятия «дискурсивная иноязычная компетенция».

Основываясь на современных представлениях о дискурсе как о коммуникативном событии, происходящем между продуцентом и целевой аудиторией в определенном временном, пространственном и прочем контексте, мы понимаем такое коммуникативное событие как сложное единство языковой формы, значения и действия, и именно такое понимание дискурса принято отечественными исследователями и активно используется в трудах, освещающих понятие «дискурс».

Мы полагаем, что современные образовательные программы, определяющие содержание и структуру учебного процесса, направленного на формирование иноречевых компетенций на неязыковых направлениях подготовки в системе бакалавриата и далее при обучении в магистратуре, должны определять и предлагать к внедрению в образовательный контекст педагогические условия, модели и технологии как способ реализации различных инвариантов подходов к формированию искомых компетенций в системе подготовки бакалавров неязыкового профиля. В нашем случае в рамках формирования дискурсивной ино- 
язычной компетенции мы ставим перед собой цель сформировать у обучающихся понимание природы дискурса, знание о его системных характеристиках (регистр, тип / модус, жанр, функциональность / функциональный стиль и формальность [3]), научить будущих бакалавров решать широкий диапазон коммуникативных задач за счёт знания и понимания особенностей речевого взаимодействия, присущих тому или иному дискурсивному сообществу, и таким образом способствовать решению проблемы формирования дискурсивной иноязычной компетенции продвинутого и высокого уровня, что позволит им справляться с широким диапазоном коммуникативных вызовов межличностного и профессионального характера на иностранном языке.

Очевидно, что обобщенные результаты исследований в области теории дискурса могут быть обращены в прикладную сферу, и дискурсивная иноязычная компетенция наряду с языковой, речевой может выступать ключевым компонентом при формировании коммуникативной иноязычной компетенции в целом и сделать своей принадлежностью социокультурную компетенциию в силу объективных предпосылок для этого.

Принимая во внимание то обстоятельство, что идеи исследователей в области дискурс-анализа почти не имеют приложения в педагогических целях, наше обращение к последним достижениям в теории дискурса, по сути, представляет собой попытку создать синергию филологической и педагогической науки, что призвано в рамках образовательного процесса закрепить у студента понимание того, как язык общения реализуется на практике, и развить способность будущих бакалавров неязыковых направлений подготовки к эффективной иноречевой коммуникации. Наше обращение к дискурс-анализу не сводится лишь к описанию лингвистических структур отдельно от их целей и функций, для реализации которых эти лингвистические структуры были созданы сообразно среде коммуникации, но предопределяет непреходящее значение дискурса в ходе обучения иностранному языку в целях совершенствования иноречевых умений будущих бакалавров неязыкового профиля.

Появление сети Интернет, современных информационных коммуникационных технологий, а также прочная позиция английского языка как средства международного общения способствовали запуску механизма создания универсальной модели коммуникации, применимой в межличностном и профессионально-ориентированном общении. Успешная коммуникация в современной поликультурной и профессиональной среде сейчас во многом определяется использованием англосаксонской модели речевого взаимодействия, которая в 1966 году была, наряду с другими, описана американским исследователем Р.Б. Капланом. Он установил прямую взаимосвязь между мыслями представителей различных узусов и тем, как эти мысли находят своё выражение в языке. Были выделены пять типичных моделей реализации речевой интенции, соотнесённые с языковыми группами, среди которых: 1) англосаксонская, 2) семитская, 3) восточная, 4) романская, 5) русская [4].

В связи с тем, что выше был заявлен тезис о том, что сформированная дискурсивная иноязычная ком- петенция продвинутого и высокого уровня обеспечивает эффективное взаимодействие как межличностного, так и профессионального характера, мы полагаем, что такое взаимодействие на иностранном языке может быть реализовано с помощью англосаксонской модели речевого взаимодействия, которая в первую очередь нацелена на успех коммуникации и тяготеет к идее прагматизма, что делает возможным однозначно толковать заложенные в неё смыслы.

В 1975 году исследователь Г.П. Грайс, преследуя идею прагматизма, разработал основные принципы речевого взаимодействия, которые были представлены как:

- максима объёма (высказывание должно быть максимально информативным, но не избыточным);

- максима качества (высказывание должно быть максимально точным и объективным в смысле содержания и не предлагать собеседнику утверждения, истинность которых может быть легко подвергнута сомнению);

- максима соответствия (высказывание должно соответствовать коммуникативной задаче и исключать какие бы то ни было смысловые девиации);

- максима восприятия (стратегия порождения высказывания должна тяготеть к ясности и четкости фразирования мысли, демонстрировать отсутствие двусмысленности, краткость, структурированность, что, в целом, определяет уровень комфорта целевой аудитории при восприятии речевого произведения) [5].

Таким образом, порождение англосаксонской модели речевого взаимодействия сообразно коммуникативной задаче в соответствии с принципами Г.П. Грайса требует от коммуниканта продемонстрировать умение обобщить обстоятельства адекватно существующей среде коммуникации, сформировать тематический фрейм, разработать сценарий локуции в границах заданной темы и с опорой на общеизвестные политические, экономические и социокультурные реалии, которые целевая аудитория воспринимает в условиях определенного когнитивного комфорта, породить речевое произведение, которому свойственна жесткая линейная структура, понятная аудитории логика, целостность и завершённость. Кроме того, как было отмечено выше, такое речевое произведение должно иметь ярко выраженный экстралингвистический фактор, что позволяет целевой аудитории декодировать широкую палитру смыслов как профессионального, так и межличностного характера, так как именно в дискурсе и через дискурс реализуется способность к когниции и к коммуникации в целом.

Отметим также, что программы обучения иностранному языку в системе подготовки бакалавров должны предусматривать необходимость и возможность переобучения с дискурса родного языка на дискурс изучаемого языка, т. е. на англосаксонскую модель речевого взаимодействия.

Все стратегии речевого взаимодействия англосаксонской модели имеют линейный характер (рис. 1).

Первый тип речевой стратегии соответствует жанровой схеме, предложенной У. Чейфом, «ориентация - завязка - кульминация - развязка (заключительный констатив) - кода» [6]. Такую структуру высказывания, как правило, можно упростить до «введение - 
развитие сюжета / основная часть - кульминация / заключительный констатив». Линейная структура англосаксонской модели речевого взаимодействия позволяет целевой аудитории легко декодировать кульминационный компонент локуции. В зависимости от сценарного замысла введение или заключение как структурные компоненты могут быть интегрированы в основную часть речевого произведения и в заключительный констатив соответственно.
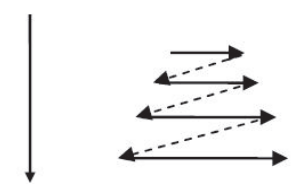

английский семитский
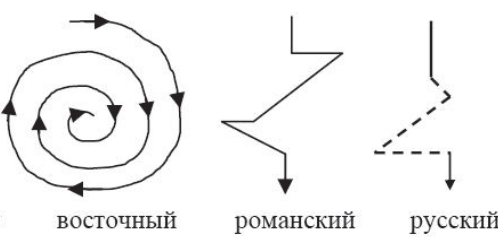

Рисунок 1 - Модели реализации речевой интенции в соотнесении с языковыми группами

Второй тип речевой стратегии - параллельно развиваюшиеся сюжетные линии, от двух и более. Данный тип речевой стратегии представляется нам трудоемким и требующим тщательной проработки, значительных временных ресурсов и более глубоких филологических познаний, которыми обучающиеся на неязыковых направлениях профессиональной подготовки в системе бакалавриата, как правило, не обладают.

Третий тип речевой стратегии - реверсивный, который обусловливает изменение полюса отнотения иелевой аудитории к предмету разговора: от отрицательного к положительному. Такой тип речевой стратегии требует определенного уровня ораторского искусства, который отражает высокий тезаурусный уровень организации языковой личности. Такая риторика относится к категории 'домашних заготовок', соотнесенных с определенным местом, временем, событием и целевой аудиторией. Как правило, такой тип речевой стратегии высказывания требует от продуцента способности удерживать внимание целевой аудитории в течение достаточно продолжительного времени, необходимого для успешной реализации тактического замысла высказывания [7, с. 15].

Так же как и тип стратегии с параллельно развивающимися сюжетными линиями реверсивная стратегия порождения речевого произведения представляется нам трудоемкой и требующей значительных временных ресурсов и более глубоких филологических познаний [7, с. 15].

Полагаем, что при работе в условиях жесткого временного ограничения рамками учебного занятия в группе, обусловленного быстро изменяющимся контекстом среды коммуникации, риторика с использованием второго и третьего типов стратегии речевого взаимодействия не представляется возможной.

Рассмотрев три возможных типа речевой стратегии порождения дискурса сообразно англосаксонской модели речевого взаимодействия, мы приходим к выводу о том, что первый из них является наиболее прагматичным, исходя из целей и задач учебного занятия. При реализации такой модели речевого взаимодействия продуцент имеет возможность с опорой на структуру вопроса / коммуникативной задачи быстро сформировать тематический фрейм, выбрать соответствующую коммуникативной задаче стратегию порождения дискурса, разработать сценарий ло- куции, определив последовательность важных для раскрытия замысла эпизодов (констативов), и без каких-либо смысловых девиаций предложить вниманию целевой аудитории структурированное, целостное и завершенное речевое произведение, соотнесенное со средой коммуникации и понятными для целевой аудитории социокультурными или профессиональными реалиями.

Итак, решение широкого диапазона коммуникативных задач требует от будущих бакалавров способности к порождению речевого произведения, или дискурса, в ходе которого реализуются основные принципы сотрудничества Г.П. Грайса [5], а также умение в течение короткого промежутка времени проанализировать и обобщить обстоятельства, относящиеся к их личному опыту и/или опыту дискурсивного сообщества, членами, которого они являются; сформировать тематический фрейм; разработать сценарий речевого произведения в границах и с опорой на структуру поставленной перед ними коммуникативной задачи; и породить дискурс, которому также свойственна жесткая структура и соотнесенность с опытом и профессиональными знаниями целевой аудитории и контекстом среды коммуникации. Кроме того, как было отмечено выше, такое речевое взаимодействие будет иметь ярко выраженный экстралингвистический фактор, возникающий в силу обстоятельств, которые подробно описаны и систематизированы в работах по анализу дискурса и психолингвистике.

Таким образом, представленный выше подход к формированию дискурсивной иноязычной компетенции позволяет нам определить англосаксонскую модель речевого взаимодействия как речевой конструкт, отвечающий целям и задачам обучения иностранному языку на неязыковых направлениях профессиональной подготовки в системе бакалавриата. Англосаксонская модель речевого взаимодействия линейна, обладает своим алгоритмом для решения широкого спектра коммуникативных задач и может быть эффективно использована в учебных целях. Знание и понимание студентами англосаксонской модели речевого взаимодействия как эффективного инструмента реализации иноречевой интенции способствует переобучению будущих бакалавров с модели коммуникации на родном языке на дискурс изучаемого языка.

Использование англосаксонской модели для решения широкого спектра коммуникативных задач в значительной степени сопряжено с понятием «дискурсивная формула». Обзор результатов исследований в области теории речевых актов позволил прийти к выводу о том, что для решения каждой коммуникативной задачи существует своя дискурсивная формула [8, с. 280], выполняющая структурно-образующую функцию. Мы понимаем под термином «дискурсивная формула» речевой сценарий различной структурной организации и соотнесенности с ситуацией коммуникации, алгоритм которого способствует простому и эффективному решению коммуникативной задачи и достижению цели коммуникации.

Такое понимание термина «дискурсивная формула» позволяет дать определение термину «англосаксонская модель речевого взаимодействия» как модели речевого взаимодействия, имеющей линейный алгоритм с различной структурной организацией $u$ 
направленной на достижение иели коммуникации в границах поставленной коммуникативной задачи.

Вышесказанное позволяет в педагогических целях дать определение понятию «дискурсивная иноязычная компетенция» как способности участника речевого взаимодействия воспринимать и порождать дискурс на иностранном языке, то есть интерпретировать и использовать тезаурус того или иного дискурсивного сообщества в процессе продуцирования или декодирования дискурсов и через понимание системных характеристик дискурса демонстрировать умение в условиях социально, культурно, профессионально и идеологически обусловленной ситуации речевого взаимодействия на иностранном языке организовать языковой материал в композиционно оформленное, целостное и завершенное речевое произведение, направленное на решение поставленной перед участниками диалога коммуникативной задачи.

Наряду с определением термина «дискурсивная иноязычная компетенция», основываясь на синергии филологической и педагогической науки, мы в педагогических целях выявили аспекты содержания данной компетенции: лингвистический, функциональный, когнитивный, эмоционально-мотивационный и перцептивный, поведенческий; определили структуру искомой компетенции, которая включает системный, лингвистический, жанровый, социокультурный, формальный, стратегический, тактический и прагматический компоненты соотнесенно с тремя классами употребления дискурса [9].

Результаты проведенного нами исследования актуальны для разработки учебно-методических комплексов, в основу которых положены дискурсивные практики, обеспечивающие будущим бакалаврам комфортное вхождение в процесс обмена информацией на иностранном языке на уровне международных контактов по темам профессионального и межличностного характера, а также развития их профессиональной и образовательной траектории, когда дело касается иноречевого взаимодействия в профессиональных и образовательных целях.
Перспективным направлением исследования проблемы формирования дискурсивной иноязычной компетенции будущих бакалавров неязыковых направлений подготовки может быть роль данной компетенции в становлении проектной культуры выпускника вуза, а также ретроспективный эффект воздействия дискурсивных иноязычных практик на модель речевого взаимодействия на родном языке.

\section{СПИСОК ЛИТЕРАТУРЫ:}

1. Горбунов А.Г. Технология формирования дискурсивной компетенции в сфере устного общения студентов нефилологического профиля // Казанский педагогический журнал. 2013. № 4. С. 150-158.

2. Алмазова Н.И. Когнитивные аспекты формирования межкультурной компетентности при обучении иностранному языку в неязыковом вузе: автореф. дис. ... д-ра пед. наук. СПб., 2003. 47 с.

3. Кибрик А.А. Модус, жанры и другие параметры классификации дискурсов // Вопросы языкознания. 2009. № 2. C. 3-21.

4. Kaplan R.B. Cultural thought patterns in intercultural education // Language Learning, 1966. № 16. P. 120.

5. Грайс Г.П. Логика и речевое общение // Новое в зарубежной лингвистике. Вып. XVI. М.: Прогресс, 1985. C. 217-237.

6. Chafe W. Integration and involvement in speaking, writing, and oral literature // In spoken and written language: Exploring orality and literacy, ed. D. TannenNorwood: Ablex, 1982. P. 35-54.

7. Горбунов А.Г. TOEFL-ориентированные технологии формирования иноязычной дискурсивной компетенции у студентов неязыковых направлений обучения: уч.-метод. пособие. Ижевск: Удмурт. ун-т, 2012. Ч. 1. 43 с.

8. Карасик В.И. Языковой круг: личность, концепты, дискурс. Волгоград: Перемена, 2004. 390 с.

9. Горбунов А.Г. Дискурсивная иноязычная компетенция: онтологический подход // Вестник Томского государственного педагогического университета. 2014. Вып. 6. С. 167-171.

\section{SINERGISTICAL ASPECT OF DISCURSIVE FOREIGN LANGUAGE COMPETENCE DEVELOPMENT IN FUTURE BACHELORS AT NON-LANGUAGE INSTITUTIONS IN THE SYSTEM OF HIGHER EDUCATION}

(C) 2016

A.G. Gorbunov, associate professor of Chair of Professional Foreign Language for Humanities Udmurt State University, Izhevsk (Russia)

Abstract. The article presents an approach to solve the problem of foreign language competence development in future bachelors in non-language specialties. The author believes that modern educational curricula developers should pursue the idea to make it possible for future bachelors to perceive and produce textuality or dicourses in a foreign language and thus perform well developed discursive foreign language competence. Development of such competence requires that special educational conditions, tuition model and technique should become a part of tutorial methodology aimed at realizing a variety of approaches to form the competence in question in future bachelors in non-language fields. Revelation of such educational conditions and development of tuition model result from synergy of Philology and Pedagogy what allows to develop students' understanding how the language of communication functions. Their advanced and high level of discursive foreign language competence make it possible for them to efficiently discuss a wide range of topics when their everyday life and professional activities are concerned. The Anglo-Saxon model of communication is being considered as an effective means to make it possible for students to slip from their native language model of communication onto the one in the foreign language. To sum up, understanding of the nature of discourse phenomenon, its systematic features, the algorithm of the Anglo-Saxon model of communication contribute a lot to well-grounded definition of the term 'discursive foreign language competence' in pedagogical purposes. Solution to the problem of the discursive foreign language competence development provides future bachelors with a comforta- 
ble start in their specialty on the level of international contacts as well as further educational opportunities abroad as they are able to perform advanced and high level of competence when discourse practices of Anglo-Saxon model of communication are concerned. Moreover, future bachelors' ability to have discursive foreign language practices on their fingertips may retrospectively impact and improve their communication model in the native tongue.

Keywords: discursive non-language competence; synergy of philology and pedagogy; educational environment; future bachelors in non-language specialties; communication in foreign language; nature of discourse; discourse matrix; Anglo-Saxon model of communication; discursive formula; educational trajectory.

УДК $37+17.02$

\title{
НРАВСТВЕННЫЙ ОПЫТ: ПЕДАГОГИЧЕСКИЙ АСПЕКТ
}

(C) 2016

\author{
A.B. Гущина, кандидат педагогических наук, проректор по учебной и воспитательной работе \\ Мурманский арктический государственный университет, Мурманск (Россия)
}

Аннотащия. В статье обосновывается значение воспитания подрастающего поколения, источником содержания которого является хранимое в нравственной памяти ценное прошлого нравственного опыта; показывается, что человек, обладающий нравственной памятью, способен расшифровывать тексты, в которых содержится предшествующий нравственный опыт, «оживлять» культурное содержание хранимого и в культуре, и в морали нравственного опыта; раскрывается содержание понятия «нравственный опыт» и выявляются характеристики такого опыта; показывается, что идеи в сознании человека рождаются в процессе выявления несоответствия между понятиями «добро», «справедливость», «толерантность», «свобода» и др. и реальностью; показывается, как воспринимаемый учащимися образ нравственного учителя распространяет моральный свет, который, рассеивая темноту безнравственности, высвечивает ценности добра, милосердия, справедливости и др., отбрасывает «моральную тень» на взаимоотношения учителя и ученика; объясняется, что нравственное поле притяжения учителя и учащихся возникает во взаимном проникновении их «моральных теней»; объясняется суть полноты добродетели, суть полноты золотого правила нравственности; делается вывод, что в основу современного образования должны быть положены ценности, которые учащийся, студент черпает из прошлого и настоящего нравственного опыта.

Ключевые слова: воспитание; учитель; учащийся; нравственная память; нравственный опыт; источник; нравственность; текст; расшифровка текста; идея; нравственное поле притяжения; добродетель; золотое правило нравственности; ценность.

Воспитание подрастающего поколения - это важная социально-нравственная и педагогическая проблема. Ее решение удовлетворяет объективную потребность общества в нравственном человеке. При решении многообразных проблем современности такой человек ориентируется на достижение блага для себя и для других, осознает, что его действия и поступки не могут не затрагивать интересы других людей, несет ответственность перед настоящим и будущим поколениями. В нравственной памяти такого человека хранится ценное прошлого нравственного опыта. Вынимая из «утаенного» плана сознания определявшие прошлый нравственный опыт моральные смыслы, нравственный человек извлекает скрывающиеся за ними многочисленные конкретные значения. Человек, обладающий нравственной памятью, способен «расшифровать текст (самый древний или только что родившийся - не имеет значения) и ответить (хоть как-то, пусть и не адекватно прообразу) на него своей мыслью, своим чувством, своим словом» [1, с. 24].

Расшифровывая тексты, в которых содержится предшествующий нравственный опыт, он обнаруживает его в культуре. Нравственный человек, «оживляя» культурное содержание опыта, «оживляет» и являющийся частью культурного опыта человечества нравственный опыт, который хранится и в культуре, и в морали, вырастающей «на ветви аксиологической категории культуры» [2, с. 231]. Нравственный опыт, хранимый в культуре, в морали является источником нравственности человека.

Сделаем пояснения относительно содержания понятия «нравственный опыт».
Нравственный опыт, как подчеркивает Р.Г. Апресян, лексически «ассоциируется с такого рода ориентациями, решениями, действиями людей, которые оформлены в конкретных отношениях товарищества и любви, брака и семьи, групповой солидарности, привязанности к родным пенатам и обязанностей перед отчизной» [3, с. 311].

Характеристикой нравственного опыта, как показывает анализ идей Р.Г. Апресяна, являются связывающие людей отношения с другими людьми, с отчизной, с различными сторонами действительности. В то же время предлагаемое Р.Г. Апресяном определение понятия «нравственный опыт» как общее определение нуждается в конкретизации. Такая конкретизация должна начинаться с осмысления понятия «опыт», которое является родовым по отношению к понятию «нравственный опыт».

При осуществлении конкретизации предлагаемого Р.Г. Апресяном общего определения понятия «нравственный опыт» мы исходим из того, что для понимания сути нравственного опыта признания наличия связывающих людей отношений, привязанности людей к родному очагу, обязанностей перед отчизной недостаточно. Подтверждение сказанному мы находим у В.Н. Сагатовского, отмечающего, что опыт не может сводиться только к непосредственной связи с миром: «В опыт должны войти любые способы человеческого взаимодействия с любыми возможными явлениями, уровнями и аспектами мира без редуцирования их к познанию» [4, с. 27]. В процессе взаимодействия с миром человек как субъект не просто по- 